\title{
Gir tidlig vurdering og behandling hos spesialist i fysikalsk medisin og rehabilitering reduksjon i langtidsfravær hos sykmeldte med muskel- og skjelettsykdommer?
}

\author{
Harald Elvsåshagen ${ }^{1}$, Gunnar Tellnes ${ }^{2}$ og Michael H. Abdelnoor ${ }^{3}$ \\ 1) NAV Vestfold og Allmennpraksis i Stavern \\ 2) Seksjon for sosialmedisin, Institutt for allmenn- og samfunnsmedisin, Universitetet i Oslo \\ 3) Senter for klinisk forskning, Ullevål Universitetssykehus, Oslo \\ Korrespondanse: Harald Elvsåshagen, Gusland, 3294 Stavern E-post: elvsaash@online.no
}

\begin{abstract}
SAMMENDRAG
Bakgrunn: De fleste langtidssykmeldte med muskel- og skjelettsykdommer blir utredet, behandlet og fulgt opp av fastlege. Ved lengre tids sykmelding henvises mange fra sin fastlege til spesialist i fysikalsk medisin og rehabilitering for å optimalisere behandlingsopplegget.

Formålet med denne studien var å undersøke om henvisning direkte fra NAV til spesialist uten å gå veien om fastlege, medførte redusert antall sykmeldingsdager og mindre bruk av andre trygdeytelser som rehabiliteringspenger, yrkesrettet attføring og uførepensjon.

Materiale og metode: I samarbeid med 14 NAV-kontor i Vestfold ble 829 sykmeldte i alder 25-50 år med 8-12 ukers sykmelding for muskel- og skjelettsykdommer randomisert til en intervensjonsgruppe $(n=409)$ og en kontrollgruppe $(\mathrm{n}=420)$. Eksklusjonskriterier var manglende arbeidsforhold, revmatiske sykdommer, brudd og leddsykdommer. Intervensjonsgruppen ble undersøkt og behandlet av spesialist i fysikalsk medisin og rehabilitering, Spesialsykehuset for rehabilitering, avd. Stavern. Kontrollgruppen fortsatte behandling hos sin fastlege. Noen av disse pasientene ble henvist til samme poliklinikk eller til annen spesialist på initiativ fra sin fastlege. Data for sykmeldingsdager, uførepensjon, rehabiliteringspenger og attføringspenger ble samlet inn fra NAV-kontorene. De samme parametre ble brukt som endepunkter. Etter to år ble endepunktene analysert. Data ble analysert etter "intention to treat"- prinsippet.
\end{abstract}

Resultater: I intervensjonsgruppen var gjennomsnittlig antall sykmeldingsdager 138 dager (SD 86,2) mot 147 dager (SD 88,0) i kontrollgruppen, en forskjell på ni sykmeldingsdager. Forskjellen er ikke statistisk signifikant $(\mathrm{p}=0,163)$. Det var heller ikke statistisk signifikant forskjell i forbruket av yrkesrettet attføring og rehabiliteringspenger mellom intervensjonsgruppen og behandlingsgruppen.

Konklusjon: Henvisning til spesialist i fysikalsk medisin og rehabilitering direkte fra NAV etter 8-12 ukers sykmelding, det vil si uten behovsvurdering hos egen fastlege, førte ikke til en statistisk signifikant reduksjon i varigheten av sykmeldingsperioden i denne studien. Heller ikke andre trygdeytelser som rehabiliteringspenger og yrkesrettet attøring ble redusert etter en observasjonsperiode på to år etter at pasientene ble inkludert i undersøkelsen.

Elvsåshagen H, Tellnes G, Abdelnoor MH. Does early intervention by a specialist in physical medicine and rehabilitation reduce the duration of long term sick leave among persons with musculoskeletal diseases? Nor J Epidemiol 2009; 19 (2): 219-222.

\section{ENGLISH SUMMARY}

Background: Most patients with long term sick leave due to musculoskeletal diseases are treated by general practitioners.

The aim of this study was to test the hypothesis that early intervention by a specialist in physical medicine and rehabilitation will reduce the duration of long term sick leave due to musculoskeletal diseases.

Material and methods: In collaboration with 14 National Insurance Offices in the Norwegian county of Vestfold, 829 patients aged 25-50 years with 8-12 weeks of sick leave for musculoskeletal diseases were included and randomized into an intervention group $(n=409)$ and a control group $(n=420)$. Exclusion criteria were no job, rheumatic diseases, fractures and joint diseases. The intervention group was examined by a specialist in Physical Medicine and Rehabilitation at the Hospital of Rehabilitation in Stavern, Norway, where they were examined and treated. The patients in the control group were treated by general practitioners as usual. Some of these patients were also referred to the same hospital or other specialists for examination as part of the general practitioner's own initiative. Data on sick leave, disability pension, and other social benefits were collected from the National Insurance Offices. Number of days of sick leave, rehabilitation benefits and vocational rehabilitation were used as end points. After two years of follow-up the end points were examined. The data were analyzed according to the "intention to treat" principle.

Results: In the intervention group the average number of sick days was 138 as compared to 147 days in the control group. The difference of nine days of sick leave was not statistically significant $(\mathrm{p}=0,163)$. Regarding rehabilitation benefits and vocational rehabilitation, the two groups did not differ.

Conclusion: Early intervention by a specialist in physical medicine and rehabilitation did not reduce the duration of long term sick leave for patients with musculoskeletal diseases in this study. After two years of observation no difference was found between the two groups in rehabilitation benefits and vocational rehabilitation. 


\section{BAKGRUNN}

Flere norske studier har vist at tidlig intervensjon kan forkorte sykefraværstiden hos sykmeldte med muskelog skjelettsykdommer. En randomisert studie blant pasienter sykmeldt for korsryggsmerter viste redusert sykefravær etter grundig klinisk undersøkelse og intervensjon tidlig i sykdomsforløpet (1). I dette prosjektet fikk pasientene informasjon og råd om å gjenoppta daglige aktiviteter selv om de følte smerte i ryggen. Etter en oppfølging på fem år, var det signifikant forskjell i uførepensjonering og tilbakegang i arbeid mellom intervensjonsgruppen og kontrollgruppen. I intervensjonsgruppen var $81 \% \mathrm{i}$ arbeid etter fem år, mot $65 \%$ i kontrollgruppen. I intervensjonsgruppen var $19 \%$ uføretrygdet mot 34\% i kontrollgruppen.

En annen randomisert studie inkluderte 457 pasienter med korsryggsmerter med 8-12 ukers sykefravær (2). Hensikten var å evaluere effekten av enkel intervensjon på kliniske og økonomiske parametre samt sykefraværslengde. Intervensjonen bestod av en klinisk undersøkelse på ryggklinikk, enkel informasjon, "trygging" og oppmuntring til normal fysisk aktivitet. Kontrollgruppen fikk oppfølging i primærhelsetjenesten. Etter tre års oppfølging hadde intervensjonsgruppen signifikant kortere varighet av sykefravær; henholdsvis 126 dager mot 170 i kontrollgruppen. Den største delen av denne forskjellen fremkom i løpet av det første året etter intervensjon.

En annen studie evaluerte tiltaket "Kjøp av helsetjenester - enklere lidelser". Studien omfattet hovedsaklig langtidssykmeldte pasienter med enklere ortopediske lidelser og enklere psykiske lidelser (3). Resultatene var usikre, blant annet fordi det var vanskeligere enn antatt å sammenligne sykmeldte pasienter og andre pasienter i det offentlige helsevesen. Resultatene i analysen av tiltakets lønnsomhet gav likevel grunnlag for å mene at tiltaket samlet sett reduserte trygdeetatens utgifter til sykepenger.

En studie som evaluerte effekten av tidlig intervensjonsprogram på ryggpasienter med høy risiko for sykefravær i en ettårig oppfølgingsstudie, viste at tidlig intervensjon gav signifikant mindre kronisk smerte, mindre bruk av medisiner og mindre bruk av helsetjenester (4). Kostnadene ved behandling var signifikant mindre i tidlig intervensjonsgruppe sammenlignet med kontrollgruppen.

Studiene ovenfor indikerer mulighet for sykmeldte pasienter til å komme raskere tilbake i arbeid dersom helsevesenet gir tilbud om intervensjon tidlig i sykmeldingsperioden.

Ved søk i Pubmed har vi ikke funnet studier som har evaluert effekten på sykefravær av systematisk klinisk vurdering og behandling ved spesialist i fysikalsk medisin og rehabilitering for sykmeldte etter 8-12 ukers sykmelding sammenlignet med vanlig behandling i norsk allmennpraksis.

\section{FORMÅL}

Formålet med denne studien var å undersøke om tidlig henvisning av pasienter med sykefravær 8-12 uker på grunn av muskel- og skjelettsykdommer direkte fra NAV til spesialist i fysikalsk medisin og rehabilitering uten henvisning via fastlege, medforte reduserte antall sykmeldingsdager, og mindre bruk av andre trygdeytelser.

\section{MATERIALE OG METODE}

Studien inkluderte alle langtidssykmeldte for muskelog skjelettsykdommer som ble registrert ved alle NAV-kontorene i Vestfold i perioden 1. oktober 2002 - 30. september 2006. Disse pasientene hadde fått utfylt Sykmelding 2 (blankett RTV 11-2000) fra sin lege.

\section{Inklusjonskriterier og eksklusjonskriterier}

Følgende personer ble inkludert:

- Arbeidstakere i alderen 25-50 år

- Personer med muskel- og skjelettsykdom sykmeldt i 8-12 uker

- Personer med stabil tilknytning til arbeidslivet de siste seks måneder og med sykepengerettighet.

Følgende personer ble ekskludert:

- Personer yngre enn 25 år og eldre enn 50 år

- Personer med manglende tilknytning til arbeidslivet og/eller manglende rett til sykepenger

- Personer med revmatiske lidelser, brudd eller leddsykdom.

\section{Prosedyre}

Sykmelding 2-blankettene ble gjennomgått. Det ble kontrollert for arbeidsforhold, alder og diagnose for å kvalitetssikre data som skulle brukes i studien. 1474 sykmeldte, som fylte inklusjonskriteriene, ble tilskrevet og orientert om at de enten ville få tilbud på Spesialinstitusjonen for rehabilitering, eller videre oppfølging hos sin fastlege. 885 sa seg villige til å delta. Dette ble redusert til 829 etter ytterligere kontroll for inklusjonskriterier og eksklusjonskriterier. Data fra spesialisterklæringer og utfylte spørreskjemaer fra deltagerne ble innsamlet på trygdekontorene. Data om sykmeldingsdager, rehabiliteringspenger, yrkesrettet attføring og uførepensjon ble registrert fra NAVkontorenes Infotrygdsystem i perioden 2004-08. Kontrollgruppen kunne få samme tilgang til spesialist etter henvisning dersom fastlegen fant dette indisert.

\section{Intervensjon}

Personer $\mathrm{i}$ intervensjonsgruppen ble henvist direkte fra de lokale NAV-kontorene til Spesialsykehuset for rehabilitering, Stavern. Intervensjonsgruppen fikk vanlig undersøkelse på fysikalsk medisinsk poliklinikk av spesialist i fysikalsk medisin og rehabilitering og leger under spesialistutdanning i perioden 8 til 12 ukers syk- 
melding. Det ble deretter gitt råd om videre behandling, enten på sykehuset eller hos behandlere i kommunehelsetjenesten - fastlege, fysioterapeut eller kiropraktor.

Personer i kontrollgruppen fortsatte vanlig oppfølging hos sin fastlege med de behandlingsformer denne kunne tilby i samarbeid med annet helsepersonell som fysioterapeuter og kiropraktorer i kommunehelsetjenesten. Kontrollgruppen hadde også muligheten til tilbud på fysikalsk medisinsk poliklinikk, Spesialsykehuset for rehabilitering, Stavern dersom fastlegen henviste dem dit. Vi har ikke data for hvor mange dette var, heller ikke hvor mange som ble henvist til andre privatpraktiserende spesialister i fysikalsk medisin og rehabilitering.

\section{Design}

Studien ble lagt opp som en randomisert undersøkelse der gruppene ble fordelt etter blokkrandomisering utført av Kompetansesenter for klinisk forskning, Ullevål Universitetssykehus ved en av forfatterne (MA). Vi genererte en randomisert liste av pasienter ved hjelp av "permuted block random procedure" (5). En serie med lukkede, ikke gjennomskinnelige konvolutter ble brukt i denne prosedyren.

\section{Utvalgsstorrelse}

I denne studien ble klinisk signifikans vurdert til å være minst 20 dager forskjell i sykmeldingsvarighet mellom intervensjons- og kontrollgruppen. Dette var basert på klinisk erfaring at 20 dager burde være et minimum når observasjonsperioden var to år. Vi fant at variabilitet av endepunkt estimert med "pooled standard deviation" var $\mathrm{SD}=87$ dager. Dersom vi tar en type 1 feil på $5 \%$ og en styrke på $90 \%$ trengte vi 400 pasienter i hver gruppe i forsøket - totalt 800 pasienter. Inkludert i studien var 829 pasienter: 409 i behandlingsgruppen og $420 \mathrm{i}$ kontrollgruppen.

\section{Endepunkter og uavhengige variabler}

Endepunktet totalt antall sykmeldingsdager omfattet alle sykmeldingsdager i to-årsperioden inkludert sykmeldingsdager $\mathrm{i}$ arbeidsgiverperioden etter dato for inklusjon. Variabelen alder er målt som gjennomsnitt for gruppen 25-50 år. Variabelen antall år samlet utdanning består av samlet antall år i grunnskole og høyere utdanning som gjennomsnitt for intervensjonsgruppen og som gjennomsnitt for kontrollgruppen.

\section{Statistikk}

Analysen ble gjort ved "intention to treat"-prinsippet. Det vil si at alle pasientene ble analysert i den gruppen de ble randomisert til. Fordi trygdedata ble samlet inn for alle som var inkludert i forsøket, er det ingen bortfall.

For analyse av kontinuerlige endepunkt ble som mål brukt totalt antall sykmeldingsdager etter inklusjon $\mathrm{i}$ studien. "Non parametrical Mann-Whitney test" ble brukt $\mathrm{i}$ analysen fordi endepunktene ikke var normalt fordelt etter Gauss' kurve. For analyse av dikotomiserte endepunkter, dvs. rehabiliteringspenger, yrkesrettet attføring og uførepensjon, brukte vi khi-kvadrat test (5).

\section{RESULTATER}

Det ble ikke påvist signifikante forskjeller mellom intervensjonsgruppen og kontrollgruppen etter alder, utdanning og kjønn (tab 1).

\section{Endepunkter for de to gruppene}

Intervensjonsgruppen hadde gjennomsnittlig ni dager kortere sykefraværslengde enn kontrollgruppen i løpet av to-årsperioden etter inklusjon. Denne forskjellen var ikke statistisk signifikant (tab 2).

Det ble heller ikke påvist forskjell mellom kontrollog intervensjonsgruppen i forekomst av yrkesrettet attføring, rehabiliteringspenger og uførepensjon i løpet av de følgende to år etter inklusjon (tab 2).

Når det gjelder uførepensjon var observasjonstiden for kort til å gi tallstørrelse med utsagns verdi (henholdsvis fire i intervensjonsgruppen og seks i kontrollgruppen).

\section{DISKUSJON}

Analysen viste at intervensjonsgruppen hadde ni dager kortere sykmeldingslengde enn kontrollgruppen, men denne forskjellen var ikke statistisk signifikant. Det ble heller ikke påvist signifikant forskjell mellom intervensjonsgruppen og kontrollgruppen etter to års oppfølging for rehabiliteringspenger og yrkesrettet attføring.

Tabell 1. Karakteristika ved intervensjons- og kontrollgruppene. Langtidssykmeldte med muskel- og skjelettsykdommer i Vestfold, 2002-06.

\begin{tabular}{lccc}
\hline Variabel & $\begin{array}{c}\text { Intervensjon } \\
(\mathrm{n}=409)\end{array}$ & $\begin{array}{c}\text { Kontroll } \\
(\mathrm{n}=420)\end{array}$ & P-verdi \\
\hline Alder & $38,6(\mathrm{SD} 6,6)$ & $39,0(\mathrm{SD} 6,5)$ & 0,41 \\
Utdanning (år) & $12,14(\mathrm{SD} 2,3)$ & $12,1(\mathrm{SD} 2,9)$ & 0,98 \\
Menn & $195(48 \%)$ & $214(51 \%)$ & 0,57 \\
Kvinner & $214(52 \%)$ & $206(49 \%)$ & \\
\hline
\end{tabular}

Tabell 2. Totalt antall sykmeldingsdager og andre trygdeytelser to år etter inklusjon. Langtidssykmeldte med muskelog skjelettsykdommer i Vestfold, 2002-06.

\begin{tabular}{lccc}
\hline Variabel & $\begin{array}{c}\text { Intervensjon } \\
(\mathrm{n}=409)\end{array}$ & $\begin{array}{c}\text { Kontroll } \\
(\mathrm{n}=420)\end{array}$ & P-verdi \\
\hline Antall sykmeldingsdager & 138,3 (SD 86,2) & 147,3 (SD 88) & 0,16 \\
Yrkesrettet attføring & 81 & 82 & 0,91 \\
Rehabiliteringspenger & 83 & 88 & 0,81 \\
Hel uførepensjon & 4 & 6 & 0,75 \\
\hline
\end{tabular}


1474 sykmeldte ble tilskrevet med tilbud om å delta i vår undersøkelse i perioden 2002 til 2006. 829 personer ble inkludert blant de 885 som sa seg villige til å delta i studien. En svakhet ved studien var at det ikke ble samlet inn trygdedata på de som ikke deltok. I denne studien er det derfor ikke mulig å beskrive $\mathrm{i}$ hvor stor grad vårt materiale er representativt sett $\mathrm{i}$ forhold til totalmaterialet eller sett $\mathrm{i}$ forhold til de som opprinnelig sa seg villige til å delta i studien. Vi har derimot ingen grunn til å anta at vårt utvalg ikke er representativt for totalmaterialet.

Klinisk signifikans ble på forhånd fastsatt til å være minimum 20 dagers forskjell mellom intervensjons- og kontrollgruppen. Dersom vi hadde satt ni dager som klinisk signifikant verdi, måtte utvalgsstørrelsen ved en type 1-feil på 5\% og en styrke på 90 ha vært betydelig større, dvs. mer enn tusen sykmeldte pasienter $\mathrm{i}$ hver gruppe av forsøket.

I studien var det ikke bare personer $\mathrm{i}$ intervensjonsgruppen som kunne bli henvist til spesialist i fysikalsk medisin og rehabilitering. Det var også mulig for fastlegene å henvise sine pasienter fra kontrollgruppen til samme poliklinikk eller privatpraktiserende spesialist dersom de mente at dette var indisert. Denne fremgangsmåten ble valgt for at kontrollgruppen skulle representere dagens henvisnings- og behandlingsrutiner $\mathrm{i}$ norsk allmennpraksis. Vi har ikke hatt muligheter for å analysere hvor mange som ble henvist fra kontrollgruppen. Det kan være at prosjektet har påvirket fastlegenes henvisningsrutiner. Dersom flere ble henvist til spesialist fra kontrollgruppen enn det som er vanlig, vil dette påvirke våre resultater.

Ved vår studie var det kort observasjonstid for reha- biliteringspenger, yrkesrettet attføring og uførepensjon. Vi kan ikke utelukke at en lengre observasjonstid enn to år, ville ha gitt andre resultater.

Vi fant i vår studie en ikke signifikant forskjell mellom intervensjonsgruppen og kontrollgruppen på ni dagers sykemelding i løpet av en observasjonsperiode på to år. I et betydelig større utvalg kan ni dagers forskjell i sykemeldingslengde være klinisk signifikant. Når det gjaldt rehabiliteringspenger og yrkesrettet attføring var dette svært likt $\mathrm{i}$ de to grupper. Det ser ikke ut til at ni dagers forskjell i sykemeldingslengde påvirket forbruket av rehabiliteringspenger og yrkesrettet attføring. Betydningen av vår observerte forskjell med hensyn til sykemeldingslengde er uklar.

Våre funn indikerer ikke at det er hensiktsmessig for NAV å sende alle langtidssykmeldte med muskelog skjelettsykdommer direkte til spesialist, og viser på dette punkt tilsvarende funn som tidligere trygdeforskning (6). Samtidig understreker vår studie betydningen av å utføre større og kontrollerte studier for å oppnå sikre konklusjoner om hva som kan føre langtidssykmeldte pasienter med muskel- og skjelettlidelser raskere tilbake $\mathrm{i}$ arbeid.

\section{KONKLUSJON}

Studien kan tyde på at rask henvisning av alle sykmeldte 8-12 uker på grunn av muskel- og skjelettsykdommer direkte til spesialist i fysikalsk medisin og rehabilitering fra NAV, ikke medfører redusert antall sykmeldingsdager eller mindre bruk av trygdeytelser som rehabiliteringspenger og yrkesrettet attføring.

\section{REFERANSER}

1. Indahl A, et al. Five-year follow-up study of a controlled clinical trial using light mobilization and an informative approach to low back pain. Spine 1998; 23: 2625-2630.

2. Hagen EM, Eriksen HR, Ursin H. Does early intervention with a light mobilization program reduce long-term sick leave for low back pain? Spine 2000; 25: 1973-1976.

3. Lippestad JW, Christensen Ø, Harsvik TH. Kjøp av helsetjenester - enklere lidelser. Oslo: SINTEF Helse, 2005.

4. Gatchel RJ, Polatin PB, Noe C, Gardea M, Pulliam C, Thompson J. Treatment- and cost-effectiveness of early intervention for acute low-back patients: a one-year prospective study. J Occup Rehabil 2003; 13: 1-9.

5. Pocock SJ. Clinical trials - a practical approach. Chichester, UK: John Wiley \& Sons, 1990.

6. Bruusgaard D, Eriksen W. Plagsomt for pasienten, vanskelig for hjelpeapparatet og dyrt for samfunnet. Oslo: Universitetet i Oslo, Seksjon for trygdemedisin, 1997; Rapport 97:5. 